Article

\title{
Mothers and Parental Leave in Belgium: Social Inequalities in Eligibility and Uptake
}

\author{
Leen Marynissen *, Jonas Wood and Karel Neels \\ Centre for Population, Family and Health, Department of Sociology, University of Antwerp, 2000 Antwerp, Belgium; \\ E-Mails: leen.marynissen@uantwerpen.be (L.M.), jonas.wood@uantwerpen.be (N.L.), karel.neels@uantwerpen.be (N.L.) \\ * Corresponding author
}

Submitted: 11 November 2020 | Accepted: 5 April 2021 | Published: 11 June 2021

\begin{abstract}
In recent decades, many Western European countries introduced parental leave policies to support the work-family combination in families with young children. However, these parental leave schemes often exhibit employment-based eligibility criteria, so the question arises to which extent social inequalities emerge in the access to parental leave, and as a result thereof also in the uptake of parental leave. Although research on parental leave increasingly addresses the issue of inclusiveness, only a limited number of studies has yet examined individual-level differentials in parents', and especially mothers', eligibility. Using detailed register data, we develop an individual-level indicator of eligibility in Belgium and deploy it to document differentiation in mothers' eligibility by age at first birth, partnership status, migration background and education. In addition, we examine to what extent differential eligibility can explain inequalities in parental leave uptake. Our results show that a considerable share of mothers-specifically very young, single, low educated mothers and mothers with a migration background-do not meet the eligibility criteria and thus are structurally excluded from parental leave in Belgium. Furthermore, differential eligibility can account for a large part of the age and educational gradients in parental leave use, as well as differences by migration background. Eligibility cannot (fully) account for lower parental leave use by single mothers and mothers with a Moroccan or Turkish migration background. Our findings suggest that a reconsideration of eligibility criteria may be instrumental in increasing the inclusiveness of parental leave policies.
\end{abstract}

\section{Keywords}

Belgium; eligibility; inclusiveness; mothers; parental leave; social inequalities

Issue

This article is part of the issue "The Inclusiveness of Social Rights: The Case of Parental Leave Policies" edited by Sonja Blum (University of Hagen, Germany) and Ivana Dobrotić (University of Oxford, UK / University of Zagreb, Croatia).

(C) 2021 by the authors; licensee Cogitatio (Lisbon, Portugal). This article is licensed under a Creative Commons Attribution 4.0 International License (CC BY).

\section{Introduction}

Over the past decades, the focus of social policy has been widening from solely protecting against social risks to complementary 'social investment' policies aimed at reinforcing human capital and labour market integration, especially of mothers (Cantillon \& Van Lancker, 2013; Hemerijck, 2015). Work-family reconciliation policies such as early childhood education and care and parental leave play an important part in these policy expansions. Concerning the latter, Belgium exhibits a parental leave system where access to leave is conditional on strict employment-related criteria (Dobrotić \& Blum, 2019a; Mortelmans \& Fusulier, 2020). Only employed parents are entitled to parental leave. Whereas having an employment contract suffices to be eligible for parents employed in the public sector, more strict eligibility criteria related to seniority apply to parents employed in the private sector. As a result, many parents are excluded by design and especially parents with precarious labour market trajectories may find it difficult to meet the eligibility criteria for parental leave (Kil, Wood, \& Neels, 
2018; McKay, Mathieu, \& Doucet, 2016; Rostgaard, 2005). Moreover, available research documents growing proportions of individuals with atypical and unstable employment biographies in both Belgium and other European countries (Schwander \& Häusermann, 2013). This limited access to parental leave is symptomatic of social policies being related to employment positions and may lead to the adoption of alternative work-family reconciliation strategies that involve a (partial) retreat from the labour market, most often of mothers (Kühhirt, 2012; Morel, 2007). As a result, employment-related eligibility criteria may potentially reinforce existing disparities between parents with precarious labour market positions on the one hand and parents with stable labour market positions on the other (Schwander \& Häusermann, 2013). In order to gain insight into such potential inequalities, it is essential to examine which groups of parents are excluded from parental leave.

Research on parental leave increasingly addresses the issue of inclusiveness, i.e., to which extent parental leave is available to all parents. In their overview paper, Dobrotić and Blum (2019a) construct an eligibility index to measure and compare the inclusiveness of parental leave benefits in twenty-one European countries and document the increasing importance of employmentbased criteria for replacement benefits as well as gendersensitive parental leave policies. Bártová and Emery (2018) develop a new policy measure, the compensation rate, which represents the financial support an individual would receive if they were to have a child and take up the parental leave they are entitled to. This measure allows taking population heterogeneity into account in the evaluation of policy entitlements both within and between populations. Furthermore, a number of case studies scrutinise parental leave uptake by parents with a migration background and suggest that the inability to meet the eligibility criteria can at least partially explain their lower uptake (Ellingsæter, Kitterød, \& Østbakken, 2020; Kil et al., 2018; Sainsbury, 2019). Also, socio-economic inequalities are increasingly being studied. McKay et al. (2016), who compare mothers' access to parental leave in two different leave programs in Canada, find that the eligibility criteria are a key explanation for differential access to parental leave between the two programs and between families by income. Lastly, Ghysels and Van Lancker (2011) examine the distribution of public spending on parental leave among different groups of parents and conclude that leave benefits disproportionally flow to higher-income households in Belgium. Available research has thus addressed the inclusiveness of policy design and public spending on the macro level (Dobrotic \& Blum, 2019a; Ghysels \& Van Lancker, 2011), or has examined patterns of leave uptake, referring to eligibility as a key explanatory factor (Ellingsæter et al., 2020; Kil et al., 2018). Except for the studies carried out by Bártová and Emery (2018), McKay et al. (2016) and Kil et al. (2018), hitherto little research has addressed individual-level differentials in parents', and especially mothers', eligibility.
In response to this gap in knowledge, we construct an individual-level indicator of eligibility and examine the inclusiveness of Belgian parental leave policy. Descriptive analyses document which mothers are excluded by the strict employment-based eligibility criteria and examine differential eligibility by age at first birth, partnership status, migration background and level of education. Subsequently, multivariate analyses further examine to what extent differential eligibility can explain differences in the actual uptake of parental leave by age at first birth, partnership status, migration background and educational level. The contribution of this article is threefold. First, the use of unique register-based microdata enables the construction of an individual-level indicator of eligibility for parental leave. The construction of such an indicator is innovative and particularly informative as there is, hitherto, no official measurement of the share of parents that is eligible in Belgium (Mortelmans \& Fusulier, 2020). Second, this indicator allows to empirically examine which groups of parents are excluded, and to which extent differential eligibility can account for variation in the actual uptake of parental leave. Hence, we contribute to social policy research on the intersection between policy design and social inequalities in access and uptake patterns (Dobrotić \& Blum, 2019b), which may be of particular interest when reflecting on how to increase inclusiveness. To date, parental leave policy reforms most often involved benefit levels, length of leave or flexibility in uptake, rather than a relaxation of eligibility criteria (Dobrotić \& Blum, 2019a; Geisler \& Kreyenfeld, 2018). These reforms, however, only enable or stimulate higher leave uptake among those already included, thus potentially exacerbating the divide between 'parental leave rich' and 'parental leave poor' households (McKay et al., 2016; O'Brien, 2009). Third, among the countries with employment-related entitlement principles, Belgium is a particular case as it has a paid, purely employment-based parental leave system, which is, moreover, very selective because of its strict employment-related eligibility criteria (Dobrotić \& Blum, 2019b). Today, most other Western European countries with paid parental leave systems rely on a mix of both employment- and citizenship-based rights (Dobrotić \& Blum, 2019a). Hence, the Belgian setting may be of interest to policymakers in Belgium, in view of reflecting on and addressing social inequalities in access to and uptake of parental leave. Also, this case study may interest policymakers in other countries where employment-based eligibility criteria are gaining importance, as to what this may imply in terms of inclusiveness.

\section{Theoretical Perspectives on Eligibility and Inclusiveness}

Combining the Capability Approach and the life course perspective, we look into how policy design, as well as path-dependencies within life courses, may shape 
individuals' work-family reconciliation strategies. The Capability Approach argues that individuals' capabilities (i.e., real, substantive freedoms to achieve certain doings, such as parental leave uptake) crucially depend on personal, social or environmental conditions, i.e., so-called conversion factors (such as parental leave policy; see Robeyns \& Byskov, 2020; Sen, 1999). In this respect, design features of parental leave policy can either constrain or enable parents' agency (capability) in the development of work-family reconciliation strategies. Besides the length of leave, affordability (determined in part by the height of replacement benefits; see Patnaik, 2018), and normative aspects (such as workplace cultures and practices; see Koslowski \& Kadar-Satat, 2019), accessibility is key in this respect (Koslowski, Duvander, \& Moss, 2019). Different eligibility criteria, based on citizenship, employment, or a mix of both, may entail differential access for specific groups of parents. Whereas eligibility criteria such as duration of citizenship (e.g., 6 or more months, or just residency at the time of childbirth; see Dobrotić \& Blum, 2019a) give access to parental leave to almost all parents, criteria based on employment history may result in a selective character of leave rights (Dobrotić \& Blum, 2019a). Also, in line with Sen's Capability Approach, available research finds that the impact of family policies on parents' capabilities to reconcile work and childcare responsibilities differs considerably between population subgroups (Hobson, Fahlén, \& Takács, 2011; Yerkes \& Javornik, 2019).

From a life-course perspective, eligibility for parental leave-and according agency to use leave to organise the work-family combination-is path-dependent upon previous events and experiences in different life domains. Hence, in case of employment-based eligibility criteria, inherently interlinked migration histories, educational trajectories, and experiences such as union formation or dissolution, as well as the timing of the birth of a first or higher-order children, shape persons' labour market trajectories that eventually determine their access to parental leave. Previous research demonstrates that individuals (especially mothers) with a migration background, lower educated persons, and single parents more often find themselves in precarious employment positions (e.g., fixed-term contracts, temporary agency work, involuntary part-time work) or out of paid employment (Corluy \& Verbist, 2014; Herremans, Vansteenkiste, \& Sourbron, 2016; Kil, Neels, Wood, \& de Valk, 2017; Maes, Wood, \& Neels, 2018; Ruggeri \& Bird, 2014). Moreover, characteristics associated with unstable employment trajectories often coincide. For example, research reports a double disadvantage for migrant women, both in terms of gender and ethnicity. They face more difficulties than migrant men but also compared to native women in securing stable labour market positions (Mussino \& Duvander, 2016; Neels, De Wachter, \& Peeters, 2018; OECD, 2017). Kil et al. (2017) and Maes et al. (2021) also document a larger decrease in activity and employment levels after the transition to parenthood of women with a migration background than among native women in Belgium, which is related to the differential stability of employment trajectories of migrant and native women. Other Belgian research shows that individuals with a migration background are often lower educated, which also partially explains their difficult entry into stable employment (Maes et al., 2018). Hence, disadvantaged positions in several domains combine into so-called multiplicative or reinforcing disadvantages (Mussino \& Duvander, 2016), precluding specific groups of parents from taking up parental leave.

When parental leave uptake is not an option due to the inability to meet the employment-based eligibility criteria, parents potentially have to develop alternative childcare solutions. Whereas some may have sufficient financial resources to outsource childcare or have access to informal care, others may face more difficulties with organising childcare. Alternative strategies such as reducing working hours, changing jobs, flex work, exiting the labour market, or continuing unemployment or inactivity may, in turn, hinder the transition into stable employment trajectories required to be eligible to take up parental leave. Hence, a vicious circle arises. Cumulative disadvantages over the life course may result in specific groups of parents not being eligible in the first place, but also not being able to become eligible in the future. As the (in)ability to take up parental leave potentially also impacts future events (e.g., parental employment, children's wellbeing, gender equality, etc.; see Duvander \& Jans, 2009; Huerta et al., 2013; Patnaik, 2018), social inequalities in work-family reconciliation between low and high educated parents, parents with and without a migration background, single and partnered parents, and young and older parents may only grow larger.

\section{The Belgian Context}

Belgium's most common child-related leave schemes include maternity leave, paternity leave, and parental leave. Maternity leave applies to all (self-)employed and unemployed mothers and consists of a minimum of 10 (obliged) and a maximum of 15 weeks of leave at the time of childbirth during which mothers receive a relatively high income-related replacement benefit (a taxable benefit amounting $75 \%$ to $82 \%$ of the gross wage; see Mortelmans \& Fusulier, 2020). Paternity leave only applies to fathers working as employees and allows them to take leave for 10 days within the first four months after the birth of a child, during which they receive high income-related replacement benefits ( $82 \%$ of the gross wage). Parental leave is an individual, non-transferable and gender-neutral entitlement that was introduced in 1997 as an offshoot of the system of Voluntary Career Breaks that was introduced in Belgium in the 1980s (Morel, 2007). Parental leave allows each parent to take up full-time leave for a maximum of four months (three 
months during the observation period of this study, until 1 June 2012) at a low and flat-rate benefit (Mortelmans \& Fusulier, 2020; RVA Dienst Studies, 2014). From its introduction onwards, parents were entitled to take up parental leave for each child younger than 4 years. The age limit was raised to 6 years in 2005 and subsequently to 12 years in 2009. Full-time employees can opt to reduce their working hours by $50 \%$ or $20 \%$ (recently also $10 \%$ ) for a longer period, receiving a benefit that is reduced accordingly. The uptake of parental leave can be split over multiple periods depending on the sector of employment and previous work history, and periods of full-time and part-time leave can be combined (RVA Dienst Studies, 2014). Mothers and fathers can take up leave simultaneously. Furthermore, employment contracts remain unchanged during parental leave and there is protection against dismissal until three months following parental leave uptake. Finally, only parents working as employees exhibit parental leave rights, implying that the self-employed, unemployed, inactive, as well as parents enrolled in education, are excluded by design. Whereas parents employed in the public sector are eligible without any conditions in terms of working experience, parents employed in the private sector have to be working for their current employer for 12 out of 15 months before the application. Hence, parents with unstable employment trajectories are less likely to meet the eligibility criteria. These eligibility criteria have not changed since their introduction in 1997.

In addition to leave policies, which allow parents to take time to perform childcare and household tasks themselves, outsourcing policies take up a prominent role in Belgian work-family policies (Raz-Yurovich, 2014). Enrolment of 0-2.5-year-olds in (subsidised) formal childcare has exceeded the Barcelona childcare targets of $33 \%$ enrolment since the early 2000 s and nearly all children aged 2.5-6 years attend pre-primary education (OECD, 2018; Population Council, 2006). After taking up maternity leave in the months after childbirth, parental leave uptake is far from a universal practice for Belgian mothers, and most mothers who do use parental leave adopt a part-time leave schedule. Consequently, employed parents often resort to (some degree of) services providing formal childcare (or informal care arrangements) from the moment the child is three months old. Furthermore, since 2004, a generously subsidised system of Service Vouchers has allowed outsourcing household work and has proven tremendously popular (Marx \& Vandelannoote, 2015).

In conclusion, Belgian work-family reconciliation policies were introduced in the first place as 'full employment' policies, aimed at the full engagement of both men and women in the labour market, rather than to facilitate the reconciliation of work and family life (Ciccia \& Verloo, 2012; Merla \& Deven, 2019). Outsourcing policies, and to a lesser extent, leave policies (as they preserve parents' connection with the labour market), have proven instrumental in households' work-family combination, mostly enabling higher female labour force participation (Dujardin, Fonder, \& Lejeune, 2018; Raz-Yurovich \& Marx, 2019). However, the degree to which these work-family policies 'work' strongly depends on the population subgroup considered, their employment positions and related eligibility. Belgium still has a considerable gender gap in employment and particularly high female part-time employment compared to most other European countries (OECD, 2019). Despite the low employment gap between mothers and childless women (Cukrowska-Torzewska, 2016), a large educational gradient exists in maternal employment in Belgium (OECD, 2017; Wood, Neels, De Wachter, \& Kil, 2016) as well as considerable migrant-native differentials in mothers' employment after parenthood (Kil et al., 2017). Furthermore, as in many other European countries, women, migrants, low qualified and young people are disproportionally represented in precarious employment positions (Merla \& Deven, 2019).

\section{Data and Methods}

\subsection{Data}

We use the Belgian Administrative Socio-Demographic Panel (BASD-Panel) that was constructed using detailed microdata from the National Register and the Crossroads Bank for Social Security on a representative sample of women aged 15-50 years, legally residing in Belgium between 1 January 1999 and 31 December 2010. In addition to sampled women, these data include all household members residing in sampled women's households on January 1st of each observation year. The BASD-Panel provides detailed quarterly information on the labour market positions and income of all household members, as well as annual information on household composition. The analyses document eligibility and uptake of parental leave for 15,893 women who made the transition to parenthood between 2000 and 2010 and who were observed for at least five quarters before the birth of their first child (which is the period required to monitor eligibility). To obtain an overall view of the mothers' parental leave uptake, we estimate whether women ever use parental leave in the period from the birth of their first child until their youngest (potentially second, or higher order) child reaches the age limit for parental leave (which is the age of 4, 6 or 12 years depending on the year of observation and concomitant leave regulations). The measurement window may prematurely end when the end of the observation period of the BASD-Panel has been reached (i.e., 31 December 2010, or the mother reaches the age of 50 ), or in case of emigration or death.

\subsection{Variables}

The dependent variable is a dummy-variable indicating whether a mother has ever taken up parental leave 
within the measurement window (1) or not (0). The main covariates in this study are eligibility, age at the birth of the first child, whether mothers had a co-resident partner during the observation period, migration background, and level of education. A woman is considered to be eligible when the youngest child is younger than the age limit for leave uptake, and she is working in the public sector (the educational sector and public administration), or the private sector, where she is employed for her current employer for at least 12 out of the 15 preceding months. Individuals who are employed for an employer in the private sector for less than 12 out of the 15 preceding months, full-time self-employed, unemployed, or inactive are not considered eligible. The individual-level indicator of parental leave eligibility is included in the analyses as the proportion of time a mother was eligible for parental leave within the measurement window. This variable varies between $0 \%$ and $100 \%$ and is divided into deciles. Age at first birth is a categorical variable distinguishing between women aged (i) 20 or younger, (ii) 21-25, (iii) 26-30, (iv) 31-35, and (v) 36 or older at the birth of their first child. Partnership status is a dichotomous variable that distinguishes between (i) mothers who had a co-resident partner during at least one-quarter of the observation period and (ii) mothers who did not. Migration background is a categorical variable distinguishing between individuals with a Belgian, European, Turkish or Moroccan, or other non-European migration background. Also, this variable distinguishes between individuals with a first (i.e., the individual is born in a foreign country) and second (i.e., the individual is born in Belgium but at least one parent is born in a foreign country) generation migration background. Level of education is a categorical variable, measured at first birth, distinguishing between (i) no education, primary or lower secondary education (low), (ii) higher secondary education (middle), (iii) tertiary education or higher (high), and (iv) unknown.

Furthermore, we control for eligibility and leave uptake by the male partner, region, age of the youngest child at the end of the observation period, parity at the end of the observation period, year of birth of the first child, and length of the measurement window. Eligibility and leave uptake by the male partner are two dichotomous variables, distinguishing between ever (1) and never having been eligible (0) and ever (1) and never having taken up leave $(0)$ during the observation period. Region is a categorical variable, measured at first birth, distinguishing between (i) the Capital Region of Brussels, (ii) Wallonia, and (iii) Flanders. The age of the youngest child at the end of the observation period is included both as a linear and a squared term as there is a nonlinear relationship between the age of the child and leave uptake. Parity at the end of the observation period provides information on women's fertility experience within the measurement window, which is likely to be associated with the odds of leave-taking during the period considered, and which is included as a categorical variable distinguishing between (i) one child, (ii) two children, and (iii) three or more children. Finally, we include the year of birth of the first child as parental leave policy has changed and leave uptake has been rising throughout our observation period.

\subsection{Analyses}

The descriptive analyses consist of a detailed examination of mothers' eligibility in terms of the four covariates considered: age at first childbirth, partnership status, migration background and level of education. The multivariate analyses consist of two nested logit models of mothers' parental leave uptake. The first model (Model I) examines the association between leave uptake and the aforementioned four main covariates to document differential uptake of parental leave. Subsequently, the second model (Model II) includes the eligibility indicator to examine whether and to what extent differentials in eligibility can effectively explain the observed associations between leave uptake and the main covariates considered in the analysis. Both logit models include all control variables. To compare socio-economic differentials in leave uptake between models I and II (Mood, 2009), we calculate predicted probabilities in leave uptake across models assuming an average profile in terms of the other covariates included in the model, and report predicted probabilities as deviations from the grand mean of parental leave uptake to facilitate the comparison of gradients across covariates (Figure $3 a$ to $3 \mathrm{~d}$; see Biegel, Wood, \& Neels, 2021).

\section{Results}

\subsection{Descriptive Results: Social Inequalities in Eligibility}

Figure 1 represents the distribution of mothers over the categories of the eligibility indicator: $26.73 \%$ of the mothers in our sample are never eligible for parental leave, meaning that they never met the eligibility criteria within the measurement window. Hence, close to one-fourth of mothers are by default excluded from using parental leave. In contrast, $39.65 \%$ of the mothers were continuously eligible, while another $33.62 \%$ was eligible through a part of the observation window. Hence, in addition to the share of mothers that is never eligible, one third of all observed mothers were unable to meet the eligibility criteria for a least some time during the observation.

Table 1 displays the summary statistics, as well as socio-economic differentials concerning the distribution of eligibility. Table 1 shows that women who are older when entering parenthood meet the eligibility criteria more often than women who had their first child at a younger age. Furthermore, the large discrepancy between mothers that did and did not have a partner during the observation period is noteworthy: $49 \%$ of the single mothers are never eligible for parental leave. This contrasts sharply with mothers who had a partner, 


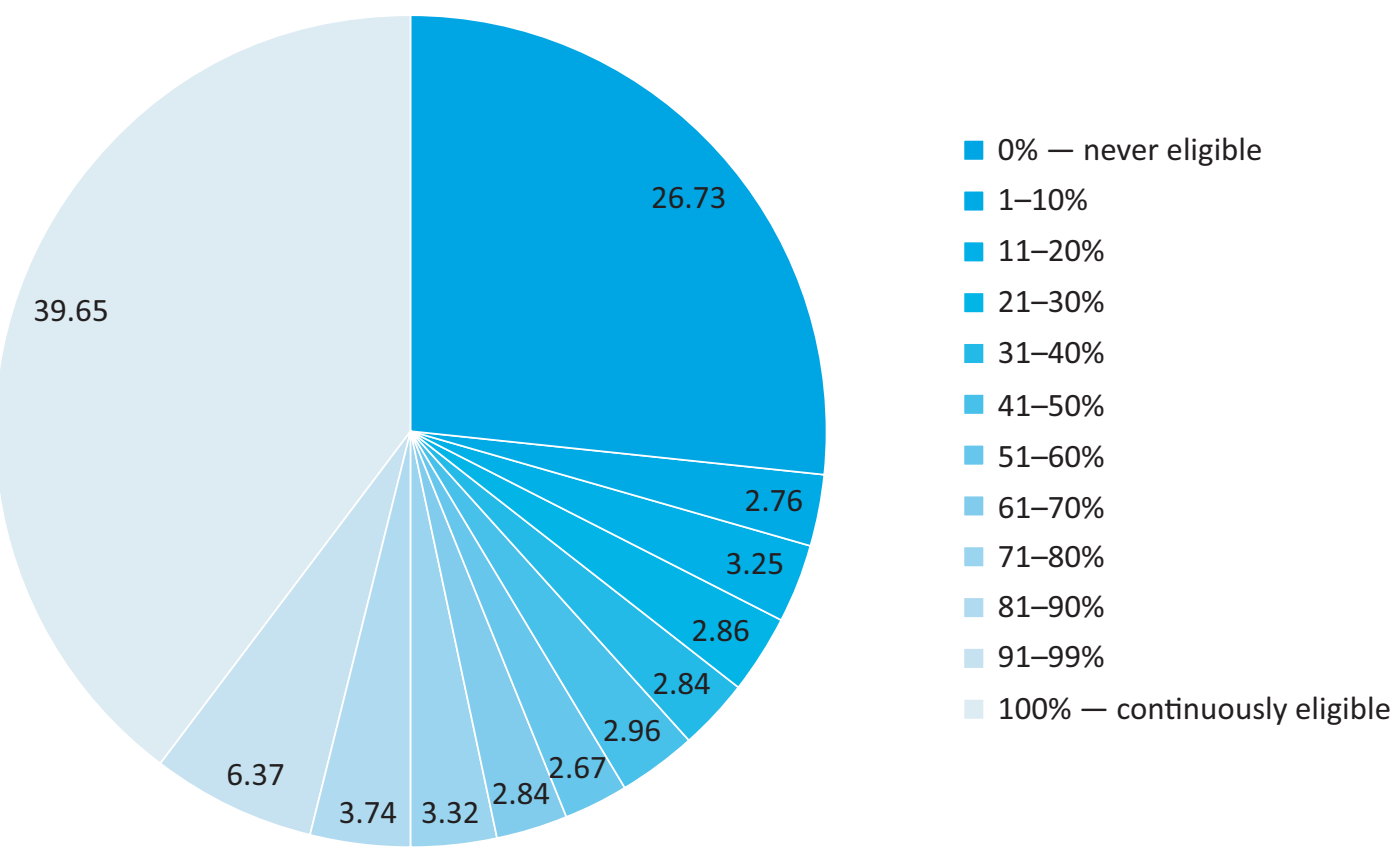

Figure 1. Distribution of the eligibility indicator 2000-2010 (proportion of time mothers were eligible for parental leave over the observation window; $N=15,893)$. Source: BASD-Panel, calculations by the authors.

of which only $24 \%$ never meets the eligibility criteria. Mothers with a non-Belgian migration background, particularly first-generation migrants and mothers originating from Turkey or Morocco, display lower levels of eligibility than mothers with no migration background. Also, an educational gradient can be discerned. Whereas $49 \%$ of the low educated mothers are never eligible, this is only $25 \%$ for middle educated mothers and $14 \%$ for high educated mothers.

In addition, mothers are less often eligible when they have two or more children compared to one, and at higher ages of the youngest child. These findings potentially reflect changes in mothers' labour force participation after the transition to parenthood, as the adaptation of employment trajectories to the number and age of children in the household may also affect mothers' eligibility for parental leave. Finally, eligibility and leave uptake of the male partner also seem to be positively correlated with mothers' eligibility, suggesting that the social inequalities in eligibility and leave uptake are exacerbated when considered at the couple level.

\subsection{Multivariate Analyses of Uptake}

Figures 2 and 3a-d display the results of two nested logit models of mothers' parental leave uptake. The weighted grand mean of parental leave uptake indicates that $37 \%$ of the mothers in our sample used parental leave. Model comparison points out that including the eligibility indicator significantly increases the model fit (Df(9), LR Chi ${ }^{2}=4025.15$, Prob $\left.>\mathrm{Chi}^{2}=0.000\right)$, and the pseudo $\mathrm{R}^{2}$ increases from $17.89 \%$ in Model I to $37.13 \%$ in Model II. The results of Model II show that concerning mothers' eligibility, a clear, almost linear pattern can be discerned (Figure 2). The higher the proportion of time a mother is eligible to take up parental leave, the higher the probability that she will also actually do so. This finding corroborates the premise that mothers with more stable employment trajectories are much more likely to use their leave entitlement than mothers with less stable or even precarious employment trajectories. However, the question remains to what extent this variation in eligibility can account for differences in parental leave uptake by mothers' age at first birth, partnership status, migration background and level of education.

Concerning mothers' age at first birth, Figure 3a (Model I) shows that deviations from the grand mean are negative at younger ages, while positive at older ages. Controlling for eligibility, differences between women with different ages at first birth become smaller and the age gradient becomes even clearer-with higher probabilities as the age at first birth increases (Figure 3a, Model II). This suggests that lower levels of eligibility of younger mothers can to a certain extent explain, though not fully, age differences in mothers' parental leave uptake. The differential in leave use between single mothers and mothers who had a co-resident partner during the observation period increases from 4 percentage points before to 6 percentage points after controlling for eligibility (Figure $3 \mathrm{~d}$ ). Furthermore, the explanatory power of mothers' eligibility is notable when considering the gradient in leave uptake by migration background and level of education. Whereas large differences in leave uptake exist between groups with different migration backgrounds in Model I, these differences disappear to a large extent when controlling for differential eligibility 
Table 1. Summary statistics and the distribution of the eligibility indicator by all covariates.

\begin{tabular}{|c|c|c|c|c|c|c|}
\hline & $\begin{array}{l}\text { No. } \\
\text { persons }\end{array}$ & $\%$ & $\begin{array}{l}0 \% \text { Never } \\
\text { eligible }\end{array}$ & $\begin{array}{c}>0 \% \\
<50 \% \text { eligible }\end{array}$ & $\begin{array}{c}\geq 50 \%, \\
<100 \% \text { eligible }\end{array}$ & $\begin{array}{c}100 \% \\
\text { Always eligible }\end{array}$ \\
\hline \multicolumn{7}{|l|}{ Leave uptake } \\
\hline No & 10,032 & 63.12 & 42.34 & 18.46 & 14.40 & 24.79 \\
\hline Yes & 5,861 & 36.88 & 0.00 & 5.99 & 28.92 & 65.09 \\
\hline \multicolumn{7}{|l|}{ Age at first birth } \\
\hline$\leq 20$ & 1,031 & 6.49 & 58.97 & 27.16 & 11.83 & 2.04 \\
\hline $21-25$ & 3,966 & 24.95 & 33.08 & 20.57 & 22.62 & 23.73 \\
\hline $26-30$ & 6,539 & 41.14 & 18.38 & 10.34 & 20.42 & 50.86 \\
\hline $31-35$ & 3,250 & 20.45 & 23.60 & 9.66 & 18.83 & 47.91 \\
\hline$\geq 36$ & 1,107 & 6.97 & 32.43 & 10.57 & 15.72 & 41.28 \\
\hline \multicolumn{7}{|l|}{ Partnership status } \\
\hline Single mother & 1,661 & 10.45 & 49.25 & 16.98 & 11.08 & 22.70 \\
\hline Having a partner & 14,232 & 89.55 & 24.10 & 13.50 & 20.77 & 41.63 \\
\hline \multicolumn{7}{|l|}{ Migration background } \\
\hline Belgium & 9,675 & 60.88 & 15.82 & 11.00 & 22.77 & 50.41 \\
\hline Europe, 1st gen & 1,373 & 8.64 & 45.88 & 15.15 & 15.37 & 23.60 \\
\hline Europe, 2nd gen & 1,407 & 8.85 & 21.75 & 17.20 & 21.54 & 39.52 \\
\hline Other non-Eu, 1st gen & 1,347 & 8.48 & 50.63 & 21.46 & 11.95 & 15.96 \\
\hline Other non-Eu, 2nd gen & 338 & 2.13 & 25.44 & 14.50 & 24.85 & 35.21 \\
\hline Turkey/Morocco, 1st gen & 1,086 & 6.83 & 67.68 & 18.88 & 6.26 & 7.18 \\
\hline Turkey/Morocco, 2nd gen & 667 & 4.20 & 41.68 & 21.89 & 16.49 & 19.94 \\
\hline \multicolumn{7}{|l|}{ Level of education } \\
\hline Low & 2,615 & 16.45 & 48.99 & 27.11 & 12.77 & 11.13 \\
\hline Middle & 4,062 & 25.56 & 24.91 & 19.84 & 23.68 & 31.56 \\
\hline High & 4,528 & 28.49 & 13.83 & 9.56 & 23.63 & 52.98 \\
\hline Unknown & 4,688 & 29.50 & 28.35 & 5.44 & 16.51 & 49.70 \\
\hline \multicolumn{7}{|l|}{ Parity } \\
\hline 1 child & 7,676 & 48.30 & 29.43 & 12.05 & 14.70 & 43.82 \\
\hline 2 children & 6,360 & 40.02 & 21.97 & 14.45 & 24.06 & 39.53 \\
\hline 3 or more children & 1,857 & 11.68 & 31.88 & 19.33 & 25.96 & 22.83 \\
\hline \multicolumn{7}{|l|}{ Age youngest child } \\
\hline$<2,5$ years & 6,898 & 43.40 & 34.14 & 9.09 & 12.53 & 44.24 \\
\hline$>2,5$ years, $<6$ years & 6,039 & 38.00 & 23.73 & 15.98 & 22.35 & 37.94 \\
\hline$>6$ years & 2,956 & 18.60 & 15.56 & 20.67 & 31.33 & 32.44 \\
\hline \multicolumn{7}{|l|}{ Eligibility partner } \\
\hline Never eligible & 4,725 & 29.73 & 45.80 & 15.39 & 12.72 & 26.10 \\
\hline Ever eligible & 11,168 & 70.27 & 18.66 & 13.22 & 22.73 & 45.39 \\
\hline \multicolumn{7}{|l|}{ Leave uptake partner } \\
\hline No uptake & 14,729 & 92.68 & 28.15 & 14.39 & 19.32 & 38.15 \\
\hline Leave uptake & 1,164 & 7.32 & 8.76 & 7.22 & 25.34 & 58.68 \\
\hline \multicolumn{7}{|l|}{ Region } \\
\hline Brussels & 2,333 & 14.68 & 42.99 & 18.00 & 14.70 & 24.30 \\
\hline Wallonia & 4,990 & 31.40 & 30.26 & 15.91 & 19.18 & 34.65 \\
\hline \multirow[t]{2}{*}{ Flanders } & 8,570 & 53.92 & 20.25 & 11.54 & 21.47 & 46.74 \\
\hline & Range & Mean & & & & \\
\hline Year & $2000 / 2010$ & 2005.30 & & & & \\
\hline \# quarters observed & $1 / 47$ & 20.34 & & & & \\
\hline Total & 15,893 & 100.00 & 26.73 & 13.86 & 19.76 & 39.65 \\
\hline
\end{tabular}

Source: BASD-Panel, calculations by the authors. 


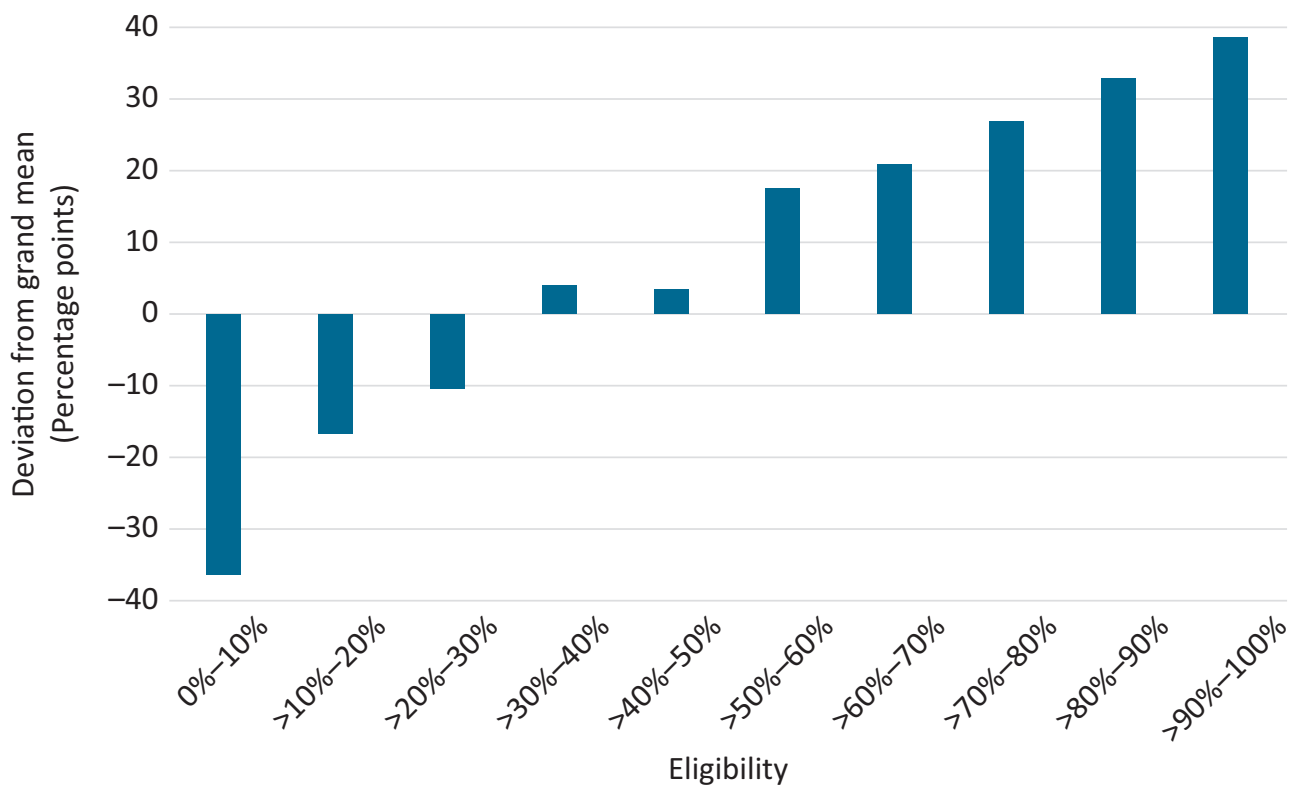

Figure 2. Predicted probabilities of leave uptake by eligibility status of the mother, expressed as deviations from the grand mean (assuming an average profile for other covariates; grand mean $=37 \%$ ), Model II, 2000-2010. Source: BASD-Panel, calculations by the authors.

a. Age at first birth

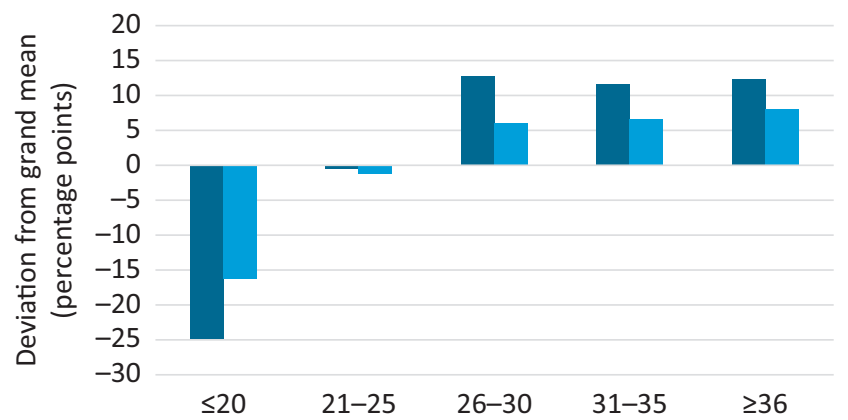

c. Migration background

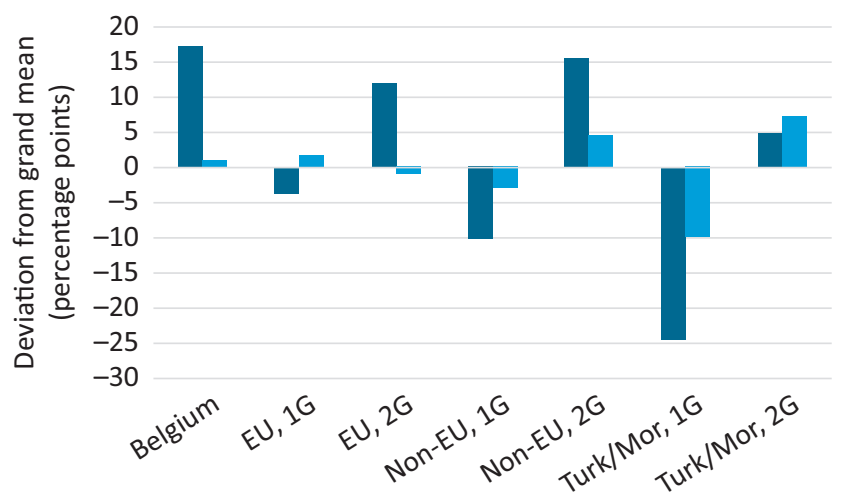

Model I b. Partnership status

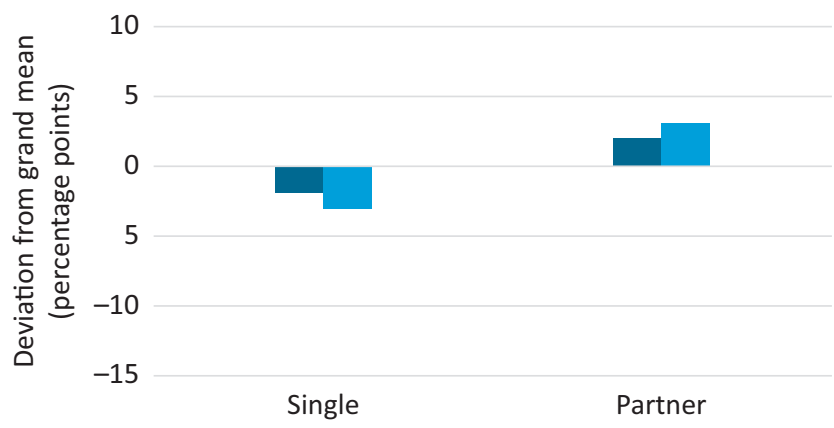

d. Level of education

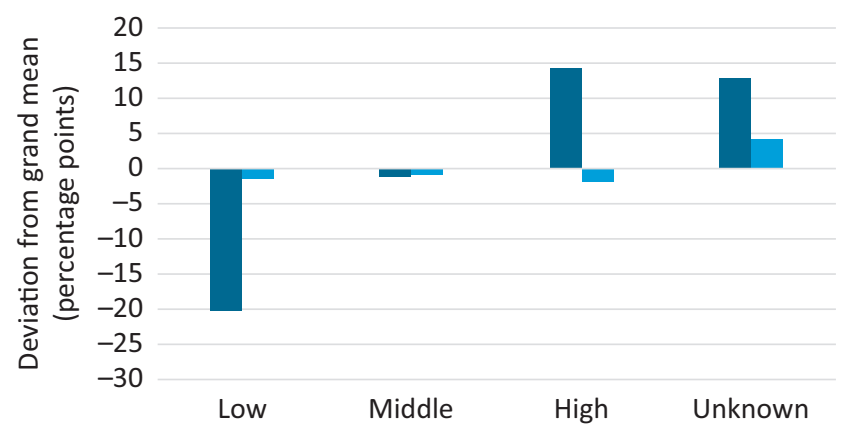

Figure 3. Predicted probabilities of leave uptake by age at first birth, parity, partnership status, migration background, and education before (Model I) and after (Model II) controlling for eligibility, expressed as deviations from the grand mean (assuming an average profile for other covariates; grand mean =37\%), 2000-2010. Source: BASD-Panel, calculations by the authors. 
in Model II (Figure 3c). In Model I, higher probabilities of leave uptake are found among women with no migration background, as well as all second-generation mothers with a migration background. In contrast, lower than average probabilities are found for first-generation mothers with a migration background-particularly those originating from Turkey or Morocco. Controlling for eligibility in Model II, the predicted probabilities for all origin groups converge towards the grand mean. Only for first and second-generation mothers with a Turkish or Moroccan migration background do the probabilities still differ significantly from the grand mean. As a result, differential eligibility almost fully explains the lower uptake of parental leave by first and second generation mothers originating from European and non-European countries, and to a large extent also for first generation Turkish and Moroccan mothers. Finally, figure 3d displays the educational gradient in mothers' parental leave uptake. A clear positive gradient can be discerned in the results of Model I, with a 35-percentage-point difference between the probabilities of leave uptake of low and highly educated mothers. Controlling for eligibility, however, this difference almost completely disappears, suggesting that differences in parental leave uptake by level of education can largely be accounted for by differential access to parental leave.

\section{Discussion}

In the last decades of the 20th century, many Western European countries introduced parental leave schemes to foster work-family reconciliation in households with young children. However, little is known about whether these leave systems actually do so for all parents, or whether their inclusiveness is limited to specific groups of parents (Dobrotić \& Blum, 2019a; Ellingsæter et al., 2020; Kil et al., 2018). Particularly when eligibility criteria are employment-based, social inequalities in the access to parental leave may be expected (McKay et al., 2016) and may provide a potential explanation for selective uptake of parental leave. Using detailed register-based microdata, we developed an individual-level indicator of eligibility in Belgium and deployed it to document differentiation in mothers' eligibility by age at first birth, partnership status, migration background and educational level. Also, this article examines the extent to which differential eligibility can explain observed patterns of differential leave uptake.

This article reaches two main conclusions. First, in Belgium, a considerable share of mothers is never eligible and thus by design structurally excluded from taking up parental leave. This group disproportionally consists of very young, single, and low educated mothers, as well as mothers with a migration background, and particularly first-generation migrants. From a life-course perspective, this finding is not surprising, given that young mothers have had less time to gain the necessary employment experience and that having a migration background, and a low level of education or being a single parent have been shown to be associated with more precarious employment positions and lower labour force participation (Herremans et al., 2016; Kil et al., 2017; Maes et al., 2018; Ruggeri \& Bird, 2014). These positions in turn hamper parents' ability to obtain access to parental leave. Furthermore, as many people find themselves at an intersection of disadvantaged positions (e.g., having a first-generation migration background and being low educated), the observed gradients in eligibility for parental leave are likely to work cumulatively and lead to the structural exclusion of a group of parents that is disadvantaged in multiple respects (Mussino \& Duvander, 2016). This is especially problematic as available research shows that these groups also experience more difficulties in accessing other social policies that foster work-family reconciliation, such as subsidised formal childcare (Biegel et al., 2021; Vande Gaer, Gijselinckx, \& Hedebouw, 2013) or subsidised outsourcing of household chores (Marx \& Vandelannoote, 2015), leading to the near exclusion of these households from the entire work-family reconciliation policy package.

Second, differential access to parental leave can account for a large part of the inequalities in uptake of parental leave in Belgium. When taking eligibility into account, the negative association between younger ages at childbirth and leave uptake decreases, migrant-native differentials to a large extent disappear and the educational gradient is no longer observed. Hence, differential eligibility can partly explain differences in leave uptake by mothers' age at first childbirth, as older parents are more likely to have already established more solid labour market positions than very young parents. However, the age gradient also becomes clearer when taking eligibility into account, indicating that other factors that differ between young and older parents-such as the ability to take parental leave with low replacement benefits (affordability) or career prospects-determine mothers' parental leave uptake. The strong decrease or even disappearance of associations between migration background and leave use, and level of education and leave use indicate that precarious employment trajectories are a key explanatory factor in social inequalities in mothers' leave use in these respects. These findings are particularly relevant as they at least suggest that a reconsideration of the aspect of eligibility in Belgian parental leave policy may decrease social inequalities in parental leave uptake to a large extent. Research on the inclusiveness of parental leave in Sweden indeed demonstrates that differences in parental leave uptake between parents with and without a migration background are small in this context with universal eligibility (Sainsbury, 2019). Concerning partnership status, our findings indicate that eligibility cannot fully explain differences in leave uptake between single mothers and mothers who had a co-resident partner during the observation period. Despite the large disparities in eligibility between mothers with and without a co-resident partner documented in the descriptive 
analyses (Table 1), the multivariate results indicate that differential eligibility does not account for the lower level of leave uptake by single mothers, suggesting that other factors are at play. In the Belgian context of low, flat rate replacement benefits, affordability may be a key factor in this respect, as there are no additional financial resources from a co-resident partner available which could mitigate the income loss associated with parental leave. Addressing such specific issues of affordability would be a fruitful path for future research. A similar conclusion can be made with respect to mothers with a Moroccan or Turkish migration background. In line with previous research, we find that although differential access to parental leave can explain part of the difference between, especially, first-generation mothers with a Moroccan or Turkish migration background and mothers without a migration background, they are still less likely to take up parental leave (Kil et al., 2018). These last findings suggest that, even when eligible, leave uptake may not be practically feasible for specific groups of parents, meaning that other factors such as benefit height, flexibility in the uptake of leave schemes, workplace cultures, or other normative factors may also shape the take-up of parental leave.

Our findings may be particularly informative as Western European countries increasingly exhibit parental leave schemes where access to replacement benefits is conditioned on employment-based criteria. In most of these countries, eligibility criteria have not been subject to reforms aimed at increasing inclusiveness since their introduction (Dobrotić \& Blum, 2019a), which is problematic as this implies that parental leave policy reforms have hitherto predominantly benefitted those already included. This article demonstrates that employment-based eligibility criteria may lead to the structural exclusion of young parents, low educated parents, single parents and parents with a migration background. It provides insight into possible avenues for addressing parental leave policies' inclusiveness, starting with re-thinking the essential first aspect of entitlement. Citizenship-based eligibility criteria or mixed systems with both citizenship- and employment-based eligibility criteria with different benefit levels depending on which criteria were fulfilled may be a part of such reflections. However, less drastic changes such as uncoupling parental leave rights from strict conditions on seniority for the same employer or employment for a more limited number of consecutive months may well enable parents with more precarious employment trajectories to use these policies to their advantage. It should be noted that to date, parental leave is - at least in Belgium-often not the single or main ingredient in parents' reconciliation strategies as it is limited in time and often deployed in a flexible manner (i.e., part-time). It is, however, exemplary of broader challenges concerning inclusiveness when access to social policies is conditioned in terms of employment positions (Biegel et al., 2021). Complementary to Esping-Andersen's concepts of decommodification and 'politics against markets,' social policies in contemporary welfare states increasingly display aspects of re-commodification by targeting labour market integration, in particular by stimulating female employment and work-family reconciliation (Cantillon \& Van Lancker, 2013; Iversen \& Soskice, 2015; Morel, 2007). However, in the context of increasing dualisation of European labour markets (Schwander \& Häusermann, 2013), such policy design features are likely to reinforce social inequalities. This is problematic for female labour force participation and work-family reconciliation after the transition to parenthood in the first place, but also entails more long-term and inter-generational consequences (e.g., women's build-up of pension rights and children's later life outcomes respectively).

Finally, we identify a number of limitations and corresponding avenues for future research. First, concerning the development of individual-level eligibility indicators, the availability of detailed information on employment sectors is crucial in case of sectoral differences in legislation. In this article, we narrowed down the public sector to the educational sector and public administration due to limited information on public versus private employment. Hence, stricter eligibility criteria for the private sector were also applied to mothers working in 'undetected' public sectors. For some mothers, this may have led to a slight underestimation of the eligibility indicator. Second, detailed registration of the duration and the degree of reduction of employment in case of leave uptake (i.e., $100 \%, 50 \%$ or $20 \%$ ) is essential to analyse duration and flexibility in uptake. Also, retrospective information of this type would allow to reconstruct whether and when exactly women have exhausted their parental leave and are for that reason no longer eligible. Given that this information is not fully available in the data at hand, for some mothers, this may have led to a slight overestimation of the eligibility indicator. Third, the analytical setup using cumulative or summary measures within a specific observation window does not allow addressing questions regarding the timing of leave uptake in relation to time-varying variables (e.g., eligibility, partnership), and potential bias could result when addressing such questions as variables measured at the time of the first birth may change throughout the measurement window. We consider this article to be an early contribution on social inequalities in eligibility for and uptake of parental leave and consider the further exploration of inequalities with respect to timing, duration and flexibility in leave uptake to constitute fruitful paths for future research.

\section{Acknowledgments}

This research was funded by the Research Foundation Flanders (FWO), grant number G.066217N.

\section{Conflict of Interests}

The authors declare no conflict of interests. 


\section{Supplementary Material}

Supplementary material for this article is available online in the format provided by the author (unedited).

\section{References}

Bártová, A., \& Emery, T. (2018). Measuring policy entitlements at the micro-level: Maternity and parental leave in Europe. Community, Work \& Family, 21(1), 33-52. https://doi.org/10.1080/13668803. 2016.1202196

Biegel, N., Wood, J., \& Neels, K. (2021). Migrant-native differentials in the uptake of (in) formal childcare in Belgium: The role of mothers' employment opportunities and care availability. Journal of Family Research. Advance online publication. https://doi. org/10.20377/jfr-463

Cantillon, B., \& Van Lancker, W. (2013). Three shortcomings of the social investment perspective. Social Policy and Society, 12(4), 553-564. https://doi.org/ 10.1017/S1474746413000080

Ciccia, R., \& Verloo, M. (2012). Parental leave regulations and the persistence of the male breadwinner model: Using fuzzy-set ideal type analysis to assess gender equality in an enlarged Europe. Journal of European Social Policy, 22(5), 507-528. https://doi. org/10.1177/0958928712456576

Corluy, V., \& Verbist, G. (2014). Can education bridge the gap? Education and the employment position of immigrants in Belgium (ImPRovE Working Paper No. 14/2). Antwerp: Herman Deleeck Centre for Social Policy, University of Antwerp.

Cukrowska-Torzewska, E. (2016). Comparative analysis of the motherhood gap in employment and wages: The role of family policies and their interaction (BWP2016/1). Budapest: Institute of Economics, Centre for Economic and Regional Studies Budapest. vDobrotić, I., \& Blum, S. (2019a). Inclusiveness of parental-leave benefits in twenty-one European countries: Measuring social and gender inequalities in leave eligibility. Social Politics: International Studies in Gender, State \& Society, 27(3), 588-614. https://doi.org/10.1093/ sp/jxz023

Dobrotić, I., \& Blum, S. (2019b). A social right? Access to leave and its relation to parents' labour market position. In Moss, P., A.-Z. Duvander, \& A. Koslowski (Eds.), Parental leave and beyond: Recent international developments, current issues and future directions (pp. 261-280). Bristol: Policy Press.

Dujardin, C., Fonder, M., \& Lejeune, B. (2018). Does formal child care availability for 0-3 year olds boost mothers' employment rate? Panel data based evidence from Belgium. Annals of Economics and Statistics/Annales d'économie et de statistique, 2018(129), 103-126.

Duvander, A.-Z., \& Jans, A.-C. (2009). Consequences of father's parental leave use: Evidence from Sweden.
Finnish Yearbook of Population Research, 44, 49-62. https://doi.org/10.23979/fypr.45044

Ellingsæter, A. L., Kitterød, R. H., \& Østbakken, K. M. (2020). Immigrants and the 'caring father': Inequality in access to and utilisation of parental leave in Norway. Ethnicities, 20(5), 959-982. https://doi.org/ 10.1177/1468796819890109

Geisler, E., \& Kreyenfeld, M. (2018). Policy reform and fathers' use of parental leave in Germany: The role of education and workplace characteristics. Journal of European Social Policy. https://doi.org/10.1177/ 0958928718765638

Ghysels, J., \& Van Lancker, W. (2011). The unequal benefits of activation: an analysis of the social distribution of family policy among families with young children. Journal of European Social Policy, 21(5), 472-485. https://doi.org/10.1177/0958928711418853

Hemerijck, A. (2015). The quiet paradigm revolution of social investment. Social Politics: International Studies in Gender, State \& Society, 22(2), 242-256. https://doi.org/10.1093/sp/jxv009

Herremans, W., Vansteenkiste, S., \& Sourbron, M. (2016). Op weg naar de arbeidsmarkt. De arbeidsmarktintrede van Vlaamse schoolverlaters [On the way to the labour market. The labour market entry of Flemish school-leavers]. Tijdschrift van het Steunpunt Werk, 26(1), 92-105.

Hobson, B., Fahlén, S., \& Takács, J. (2011). Agency and capabilities to achieve a work-life balance: A comparison of Sweden and Hungary. Social Politics: International Studies in Gender, State \& Society, 18(2), 168-198. https://doi.org/10.1093/sp/jxr007

Huerta, M. D. C., Adema, W., Baxter, J., Han, W.-J., Lausten, M., Lee, R., \& Waldfogel, J. (2013). Fathers' leave, fathers' involvement and child development: Are they related? Evidence from four OECD countries. Paris: OECD Publishing.

Iversen, T., \& Soskice, D. (2015). Politics for markets. Journal of European Social Policy, 25(1), 76-93. https:// doi.org/10.1177/0958928714556971

Kil, T., Neels, K., Wood, J., \& de Valk, H. A. (2017). Employment after parenthood: Women of migrant origin and natives compared. European Journal of Population, 34(3), 413-440. https://doi.org/10.1007/ s10680-017-9431-7

Kil, T., Wood, J., \& Neels, K. (2018). Parental leave uptake among migrant and native mothers: Can precarious employment trajectories account for the difference? Ethnicities, 18(1), 106-141. https://doi.org/10.1177/ 1468796817715292

Koslowski, A., Duvander, A.-Z., \& Moss, P. (2019). Parental leave and beyond: Recent international developments, current issues and future directions. Bristol: Policy Press.

Koslowski, A., \& Kadar-Satat, G. (2019). Fathers at work: Explaining the gaps between entitlement to leave policies and uptake. Community, Work \& Family, 22(2), 129-145. https://doi.org/10.1080/13668803. 
2018.1428174

Kühhirt, M. (2012). Childbirth and the long-term division of labour within couples: How do substitution, bargaining power, and norms affect parents' time allocation in West Germany? European Sociological Review, 28(5), 565-582.

Maes, J., Wood, J., \& Neels, K. (2018). Early labour market trajectories of intermediate and second generation Turkish and Maghreb women in Belgium. Research in Social Stratification and Mobility, 61, 65-78. https:// doi.org/10.1016/j.rssm.2018.11.001

Maes, J., Wood, J., \& Neels, K. (2021). Path-dependencies in employment trajectories around motherhood: Comparing native versus second-generation migrant women in Belgium. Journal of International Migration and Integration. Advance online publication. https://doi.org/10.1007/s12134-020-00801-1

Marx, I., \& Vandelannoote, D. (2015). Matthew runs amok: The Belgian service voucher scheme. In N. Morel \& C. Carbonnier (Eds.), The political economy of household services in Europe (pp. 197-220). Berlin: Springer.

McKay, L., Mathieu, S., \& Doucet, A. (2016). Parentalleave rich and parental-leave poor: Inequality in Canadian labour market based leave policies. Journal of Industrial Relations, 58(4), 543-562. https:// doi.org/10.1177/0022185616643558

Merla, L., \& Deven, F. (2019). The time credit system: The panacea for a life course approach? In Moss, P., A.-Z. Duvander, \& A. Koslowski (Eds.), Parental leave and beyond: Recent international developments, current issues and future directions (p. 299-313). Bristol: Policy Press.

Mood, C. (2009). Logistic regression: Why we cannot do what we think we can do, and what we can do about it. European Sociological Review, 26(1), 67-82. https://doi.org/10.1093/esr/jcp006

Morel, N. (2007). From subsidiarity to 'free choice': Childand elder-care policy reforms in France, Belgium, Germany and the Netherlands. Social Policy \& Administration, 41(6), 618-637.

Mortelmans, D., \& Fusulier, B. (2020). Belgium country note. In A. Koslowski, S. Blum, I. Dobrotić, G. Kaufman, \& P. Moss (Eds.), International review of leave policies and research 2020 (pp. 107-121). Hagen: Fakultät für Kultur- und Sozialwissen-schaften. Retrieved from http://www.leavenetwork.org/lp_ and_r_reports

Mussino, E., \& Duvander, A.-Z. (2016). Use it or save it? Migration background and parental leave uptake in Sweden. European Journal of Population, 32(2), 189-210. https://doi.org/10.1007/s10680-0159365-x

Neels, K., De Wachter, D., \& Peeters, H. (2018). The effect of family formation on the build-up of pension rights among minority ethnic groups and native women in Belgium. Ageing \& Society, 38(6), 1253-1278.

O’Brien, M. (2009). Fathers, parental leave policies, and infant quality of life: International perspectives and policy impact. The ANNALS of the American Academy of Political and Social Science, 624(1), 190-213. https://doi.org/10.1177/0002716209334349

OECD. (2017). The pursuit of gender equality: An uphill battle. Paris: OECD Publishing.

OECD. (2018). OECD data [Data set]. Retrieved from https://data.oecd.org/students/enrolment-rate-inearly-childhood-education.htm

OECD. (2019). OECD data [Data set]. Retrieved from https://data.oecd.org/emp/part-time-employmentrate.htm\#indicator-chart

Patnaik, A. (2018). Reserving time for daddy: The consequences of fathers' quotas. Journal of Labor Economics, 37(4), 1009-1059.

Population Council. (2006). Policies to reconcile labor force participation and childbearing in the European Union. Population and Development Review, 32(2), 389-393.

Raz-Yurovich, L. (2014). A transaction cost approach to outsourcing by households. Population and Development Review, 40(2), 293-309.

Raz-Yurovich, L., \& Marx, I. (2019). Outsourcing housework and highly skilled women's labour force participation-An analysis of a policy intervention. European Sociological Review, 35(2), 205-224. https://doi.org/10.1093/esr/jcz001

Robeyns, I., \& Byskov, M. F. (2020). The capability approach. The Stanford Encyclopaedia of Philosophy. Retrieved from https://plato.stanford.edu/archives/ win2020/entries/capability-approach

Rostgaard, T. (Ed.). (2005). Diversity and parental leave. Brussels: Centrum voor Bevolkings- en Gezinsstudie.

Ruggeri, K., \& Bird, C. E. (2014). Single parents and employment in Europe (Short Statistical Report No. 3) Cambridge: RAND Corporation.

RVA Dienst Studies. (2014). Ouderschapsverlof: Evolutie van de verhouding mannen/vrouwen van 2002 tot 2012 [Parental leave: Evolution of the male/female ratio from 2002 to 2012]. Brussels: RVA Dienst Studies. Retrieved from http://www.rva.be/ sites/default/files/assets/publications/Etudes/2014/ Conge_Parental/NL.pdf

Sainsbury, D. (2019). Policy constructions, immigrants' social rights and gender: The case of Swedish childcare policies. Journal of European Social Policy, 29(2), 213-227. https://doi.org/10.1177/09589287 18762311

Schwander, H., \& Häusermann, S. (2013). Who is in and who is out? A risk-based conceptualization of insiders and outsiders. Journal of European Social Policy, 23(3), 248-269. https://doi.org/10.1177/ 0958928713480064

Sen, A. (1999). Commodities and capabilities. Oxford: Oxford University Press.

Vande Gaer, E., Gijselinckx, C., \& Hedebouw, G. (2013). Het gebruik van opvang voor kinderen jonger dan 3 jaar in het Vlaamse Gewest [The use of childcare for 
children younger than age 3 in the Flemish Region] (Report No. 12). Brussels: Steunpunt Welzijn, Volksgezondheid en Gezin.

Wood, J., Neels, K., De Wachter, D., \& Kil, T. (2016). Family formation and labour force participation. Maternal employment and educational differentials in
Europe. Population, 71(1), 53-81.

Yerkes, M. A., \& Javornik, J. (2019). Creating capabilities: Childcare policies in comparative perspective. Journal of European Social Policy, 29(4), 529-544. https:// doi.org/10.1177/0958928718808421

\section{About the Authors}
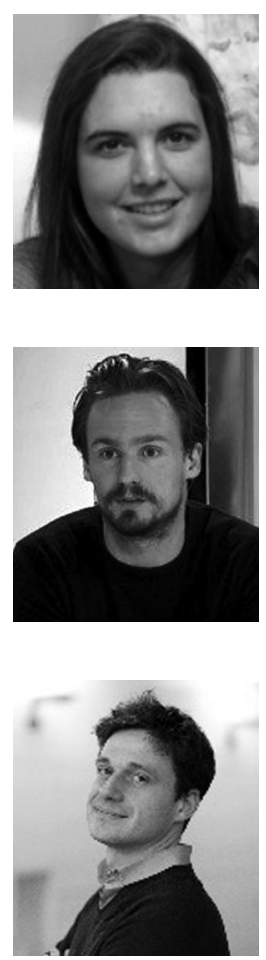

Leen Marynissen is a PhD student at the Centre for Population, Family and Health at the University of Antwerp, Belgium. She studies gender dynamics in couples' labour market positions around the transition to parenthood. Particular attention is paid to partners' relative labour market positions in relation to their transition to a first birth, as well as the uptake of parental leave. Her research comprises case studies of Belgium as well as other European countries.

Jonas Wood is appointed as Postdoctoral Researcher and Guest Professor at the University of Antwerp, Belgium. Jonas Wood studies family and labour market transitions in Belgium and Europe. Particular attention is paid to varying patterns by population subgroups such as educational groups or different migration backgrounds. In addition, context-contingencies such as the effects of economic cycles and social policies are assessed. To disentangle varying family and labour market behaviours by population subgroups and contexts, his research relies on longitudinal quantitative or mixed-method research designs.

Karel Neels is Professor of Social Statistics and Demography at the University of Antwerp, Belgium, and also teaches hazard modelling in the Master of Statistics Programme at the University of Leuven, Belgium. His research looks into trajectories of education, employment and family formation in both native and migrant populations, typically using large-scale longitudinal microdata from censuses and social security registers. 